\title{
The influence of environmental parameters on the dynamic behaviour of the San Frediano bell tower in Lucca
}

\author{
Riccardo Mario Azzara ${ }^{\mathrm{a}}$, Guido De Roeck ${ }^{\mathrm{b}}$, Maria Girardic, Cristina \\ Padovani $^{\mathrm{c}}$, Daniele Pellegrini ${ }^{\mathrm{c}}$, Edwin Reynders ${ }^{\mathrm{b}}$ \\ ${ }^{a}$ Istituto Nazionale di Geofisica e Vulcanologia (INGV), Osservatorio Sismologico di \\ Arezzo, Italy \\ ${ }^{b} K U$ Leuven, Department of Civil Engineering, Leuven, Belgium \\ ${ }^{c}$ Institute of Information Science and Technologies "A. Faedo", ISTI-CNR, Pisa, Italy
}

\begin{abstract}
This paper aims at assessing the influence of environmental parameters on the modal characteristics of age-old masonry constructions. The results of a long-term ambient vibration monitoring of the San Frediano bell tower in Lucca (Italy) are reported. The tower, dating back to the 11th century, has been fitted along its height with four triaxial seismometric stations, which were left active for about one year. Data from the monitoring system have been processed via the Stochastic Subspace Identification Method in order to identify the tower's modal characteristics and their variations over the year. The dependence of the tower's frequencies on the ambient temperature was first studied and simulated via simple auto-regressive models. Then, some output-only models based on the principal component analysis (PCA) were applied, under the hypotheses of both linear and nonlinear (Kernel PCA) dependence of the natural frequencies on the unknown environmental parameters. The results indicate PCA to be an effective tool for detecting changes in the dynamic characteristics of masonry constructions.
\end{abstract}

Key words: Masonry towers, structural health monitoring, stochastic subspace identification method, environmental variability, experimental models, principal component analysis. 


\section{Introduction}

Measuring the vibrations of masonry towers is a common practice for assessing their dynamic behaviour. The first efforts date back to the 1970s [8], when researchers began to investigate the inertia forces induced on bell towers by the swinging bells. In [25] the authors presented the results of an experimental campaign conducted on 19 church towers in England, in which the towers' accelerations during bell-swinging were measured and their fundamental frequencies identified, while in [10] the effects of bell-swinging on the dynamic behaviour of a masonry tower in Spain are analysed. In addition to the bells actions, masonry towers are subjected to a number of vibrations sources, such as traffic, micro-tremors, wind and earthquakes. The availability of even more sensitive instruments to detect towers' movements is allowing researches and engineers to conduct accurate long-term monitoring campaigns. In fact, ambient vibration monitoring can provide important information on the structural health of old masonry constructions, as it is a non-destructive technique able to capture the most important features of their dynamic behaviour, such as natural frequencies, damping ratios, mode shapes and wave propagation velocities. Once the influence of environmental factors has been accounted for, changes in these dynamic properties over time can represent effective structural damage indicators.

The literature contains few reports on long-term ambient vibration recordings on monumental buildings. Among these, paper [17] reports on the vibrations of the Mogadouro Clock Tower and the church of the Monastery of Jeronimo in Portugal, [2] studies the Garisenda and Asinelli towers in Bologna (Italy), [6] describes the dynamic monitoring of the tower of the church of San Vittore in Arcisate (Italy) and [5] deals with ambient vibration testing of the bell tower of the cathedral of Monza. Dynamic monitoring of Gabbia tower in Mantua (Italy), reported in [7] and [23], furnishes data before and after the earthquake that struck the North of Italy in May 2012: a slight permanent variation in the natural frequencies of the tower has been observed after the seismic event. In all these examples, the influence of environmental parameters such as temperature and humidity, on the measured natural frequencies of the monuments has been observed and modelled via auto-regressive models. Finally, in [26], [27] and [28] authors report on the monitoring of the San Pietro bell tower in Perugia, study the environmental effects on its natural frequencies and propose 


\section{procedures to detect damage.}

The environmental parameters affect the dynamic behaviour of monumental buildings in a peculiar way, which seems to be different from that for concrete, steel and prestressed concrete structures [14]. For example, in the cases cited above the natural frequencies of the monuments increase with temperature.Another issue arises regarding recognition of the most effective configuration of the ambient sensor network able to capture the correlation between the monument's dynamic properties and the external environment. In addition, in most cases the environmental parameters are measured in a very limited number of points on the structures. For these reasons, outputonly procedures can prove to be useful. The term "output-only" means that, given a system subjected to unknown inputs (ambient vibrations and other environmental factors), only the damage-sensitive features (natural frequencies, for example), which constitute the system's output need to be measured for the system to be characterised. A crucial point is that the variations in environmental conditions are typically much slower than the structural vibrations. Thus, for example, changes in temperature and humidity have daily or seasonal frequency, while the lowest structural eigenperiods are in the order of one or few seconds. This enables estimating the damage-sensitive features of the structure via short sequences of measured data, during which the structure behaves as a linear time-invariant system, and then considering these estimated quantities as the outputs of a global model, whose input are the unknown environmental parameters.

In this paper we present the results of long-term ambient vibration monitoring of the San Frediano bell tower in Lucca. The tower has been fitted with four three-axial high-sensitivity seismometric stations, left on the monument for about one year. The velocities recorded by the instruments have been used for the dynamic identification of the tower. The bell tower and its monitoring are described in Section 2. A preliminary experimental campaign on the tower was conducted in May 2015. The results have been presented in [1], where the tower's natural frequencies, mode shapes and modal damping ratios have been estimated from a five day dataset via the Stochastic Subspace Identification (SSI) Method [15], [19], implemented in the MACEC [20] code. In [1] a finite-element model has also been built with the NOSAITACA code [4], [12], [16] and applied to estimate the mechanical properties of the tower's constituent materials. The results presented in [1] are briefly summarized at the end of Section 3 herein, which also describes the improved identification of the tower's mode shapes obtained by merging data from dif- 
ferent sensor layouts. Most of Section 3 is devoted to data analysis. An automated SSI procedure is applied to the entire monitoring period, after dividing the velocities dataset into many one hour long sequences. During the early hours of 24 August 2016, the signal of the Amatrice earthquake, that struck central Italy with a 6.0 magnitude, was also recorded on the tower. Although Lucca is about $400 \mathrm{Km}$ far from Amatrice, the signal of the earthquake was clearly detected by the sensors, with velocities on the same order of those induced by the swinging of the bells. No significant damage was observed on the tower as a result of the seismic event.

Section 4 focuses on the influence of environmental parameters on the dynamic properties of the tower. Unlike [5], [7], [27], where only linear models are used, here a nonlinear approach is followed as well. In subsection 4.1 some Auto-Regressive eXternal input (ARX) models are applied by taking the tower's natural frequencies as output and the air temperature measured in Lucca's historic centre as input. Then, in subsection 4.2 , the procedure described in [21], which makes use of the Gaussian kernel principal component analysis (kernel PCA) to study a post-tensioned concrete bridge, is applied in order to identify output-only linear and nonlinear environmental models. These models, focused on novelty detection in signal processing, are able to automatically detect anomalies in the tower's dynamic response. They are applied to the recorded data by using different training periods and, in particular, before and after the Amatrice earthquake, in order to assess the tower's structural integrity after the event. Some simple damage scenarios are also simulated, in order to test the models' ability to detect structural damage on the structure. The results indicate that in the case under examination performances of linear PCA and kernel PCA are comparable.

Although continuous monitoring of structures is a common practice, data available from long-term measurements on historical buildings are quite scarce. Thus, the information collected and analysed in this paper on the changes in the dynamic properties of the bell tower over one year, will enhance our understanding of the dynamic behaviour of such constructions and allow for detecting any structural damages they may undergo.

\section{The San Frediano bell tower and the monitoring system}

The Basilica of San Frediano (see Figure 1) dates back to the $11^{\text {th }}$ century. It is one of the most fascinating monuments in Lucca, much of its fascination being due to the marvellous mosaics that adorn its façade, which glistens 


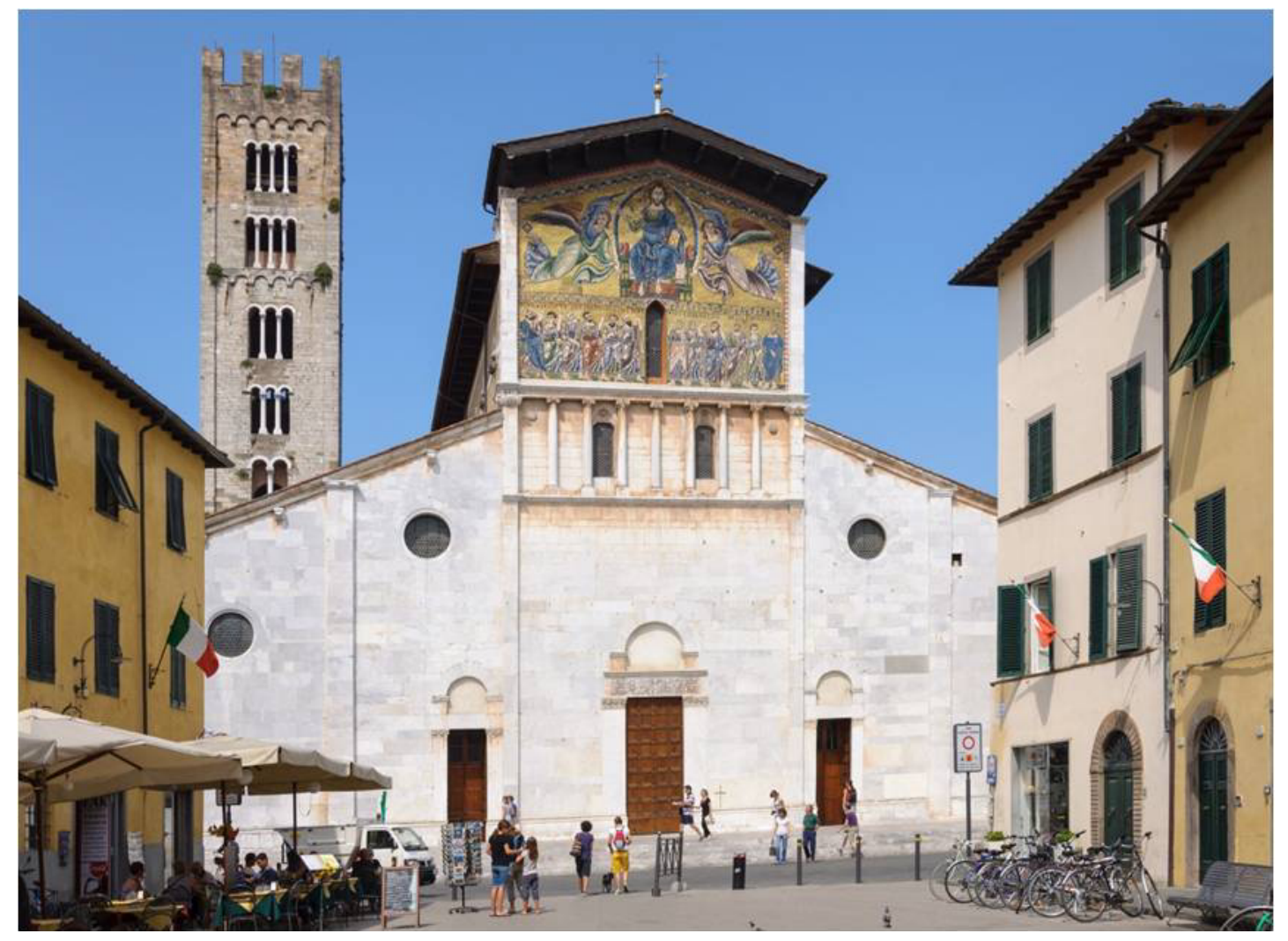

Figure 1: The Basilica of San Frediano in Lucca (Italy). On the left, the San Frediano bell tower. 


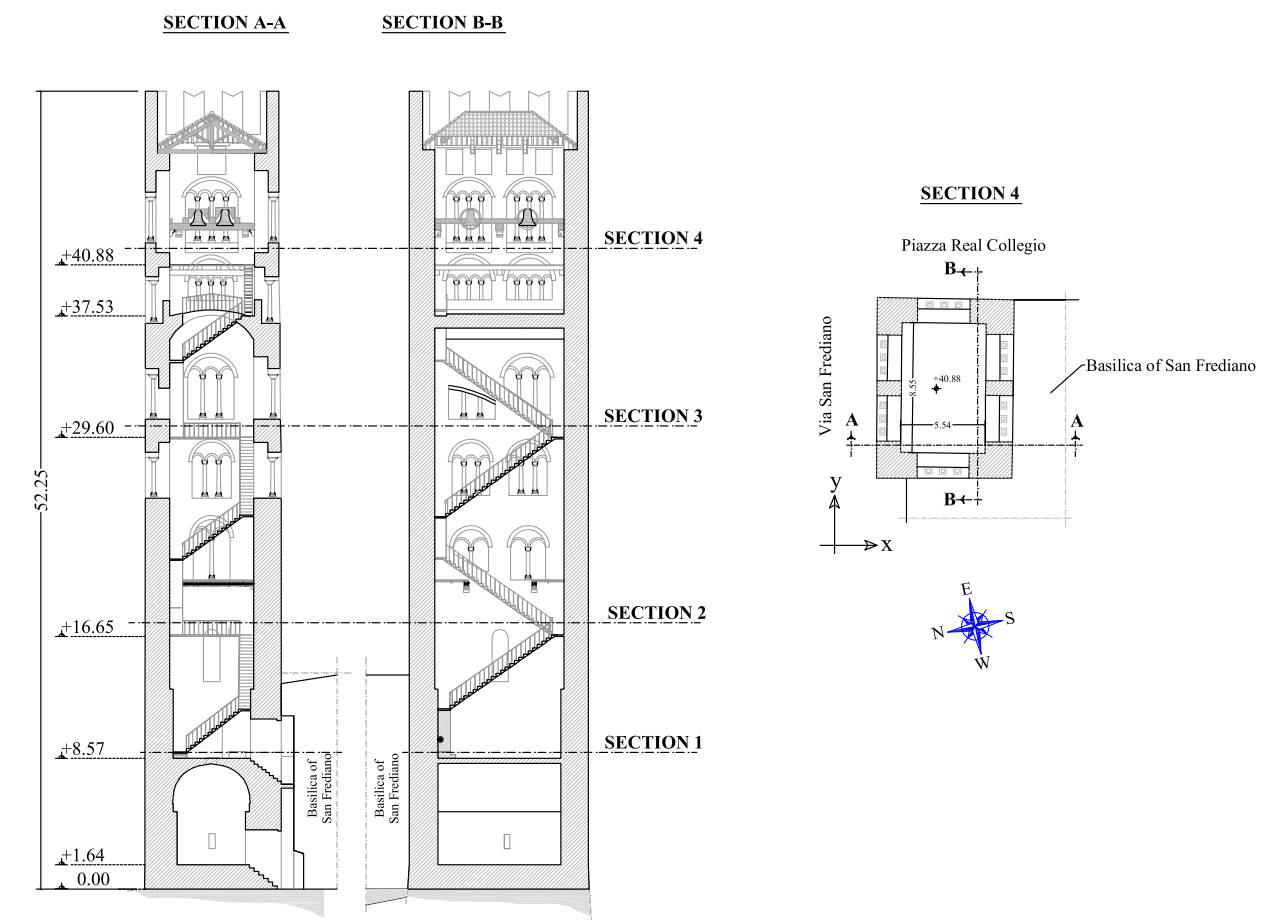

Figure 2: Sections of the tower.

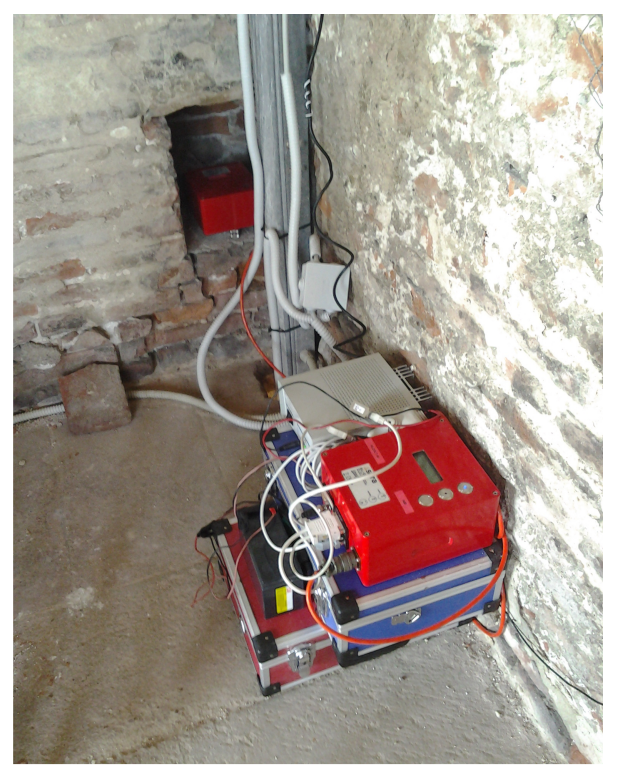

Figure 3: A seismic station on the San Frediano bell tower. 

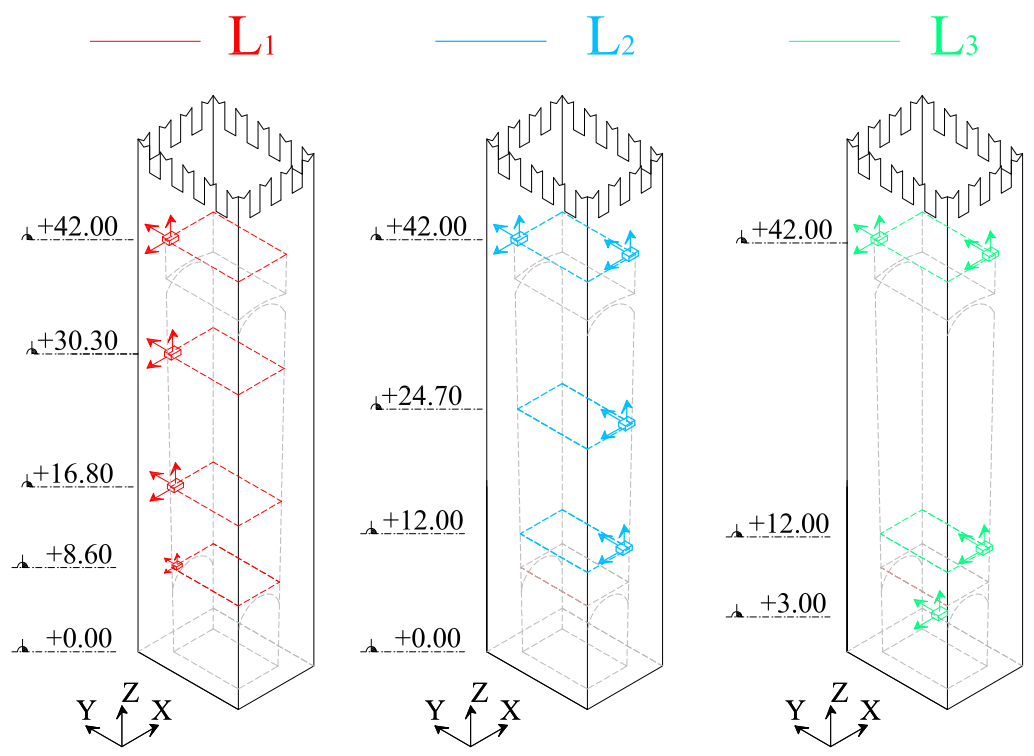

Figure 4: Sensor placements during the monitoring period. Layout $1\left(\mathrm{~L}_{1}\right)$ : from 28 May 2015 to 3 June 2015 . Layout $2\left(\mathrm{~L}_{2}\right)$ : from 28 October 2015 to 27 May 2016. Layout 3 $\left(\mathrm{L}_{3}\right)$ : from 27 May 2016 to 16 October 2016.
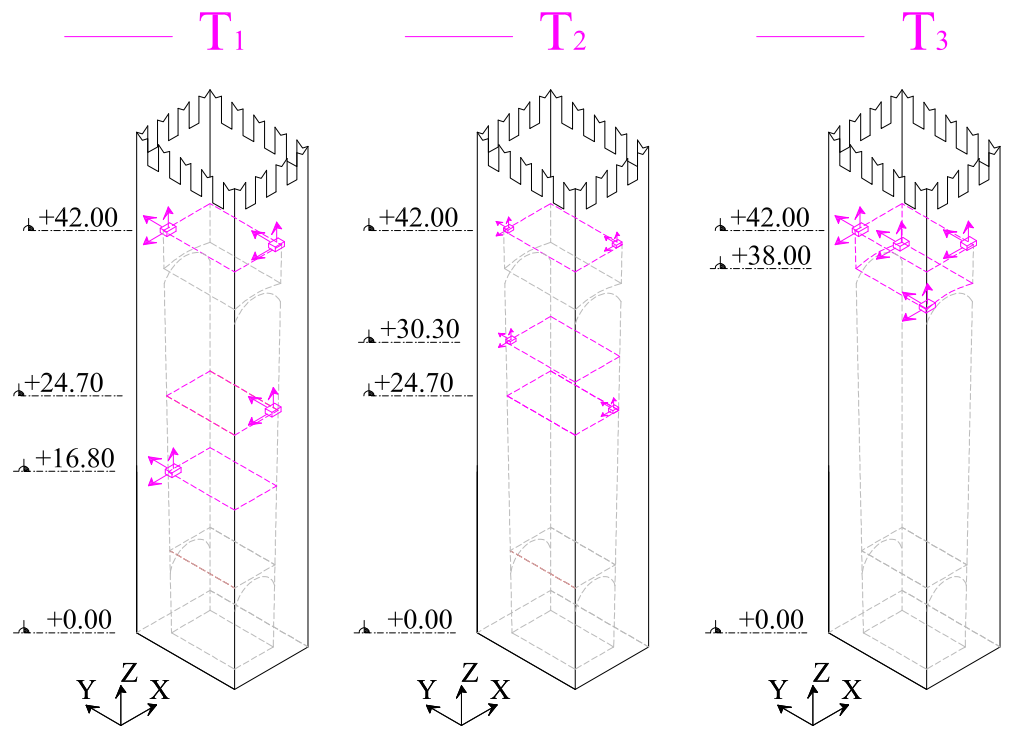

Figure 5: Sensor placements for the tests conducted on 27 May 2016. 
spectacularly in the light of the rising sun. The church's bell tower is one of the best preserved in Lucca's historic centre. It is $52 \mathrm{~m}$ high, with walls varying in thickness from about $2.1 \mathrm{~m}$ at the base to $1.6 \mathrm{~m}$ at the top. The tower is entered through a masonry staircase leading from the street level to the first floor, which is formed by a masonry vault set at a height of about $8.6 \mathrm{~m}$ (Figure 2). From this level, a stone staircase running along the inner perimeter provides access to the terminal section of the tower, about $40 \mathrm{~m}$ high, which houses the bells. The bell chamber is separated from the rest of the structure by a stiff masonry vault, which has been fitted with 4 steel tie rods of rectangular section. Over the vault, at about $43 \mathrm{~m}$, there is a walkable wooden floor, which makes it possible to reach the bells. No rigid diaphragms are present inside the tower between the two vaults: the structure's section is not stiffened for about $30 \mathrm{~m}$ 's height. The tower bears openings on all sides and is covered by a pavilion roof made up of wooden trusses and rafters in a very poor state of maintenance. The San Frediano Basilica adjoins the tower on two sides for about $13 \mathrm{~m}$ of its height. Although little information is available on the history of the bell tower, the numerous modifications made to the structure over time are clearly visible. In particular, the upper part of the structure, now hosting the bell chamber, seems to have been built later than the rest of the structure. The same appears for the bifora and trifora windows along the tower. With regard to the mechanical characteristics of its constituent materials, no experimental information is available at the moment. On visual inspection, the masonry seems to be made up of regular stone blocks at the base, while quite homogeneous brick masonry is visible in the upper section, apart from the central part of the walls, where the masonry between the windows is made up of stone blocks.

Between May and June 2015 the tower was instrumented with four SARA triaxial seismometric stations (Figure 3). Each station was equipped with a SL06 24-bit digitizer coupled to a SS20 seismometer (electrodynamic velocity transducer). The instruments, made available by the Osservatorio Sismologico of Arezzo (INGV) are usually employed in seismic monitoring networks. They were arranged on the San Frediano bell tower along a vertical line, as shown in Layout 1 of Figure 4, and left active on the tower for five days. The results of this experiment are available in [1]. Subsequently, the instruments were installed again on the tower and left active from 28 October 2015 to 16 October 2016. Over the course of this year, two main sensor layouts were chosen. In the first (reported as $L_{2}$ in Figure 4), two sensors were placed on two opposite sides of the bell chamber, and the re- 
maining aligned along the tower. In the second (reported as Layout 3 in Figure 4) one of the sensor along the tower's height was moved to the base, in order to measure ground vibrations. In this layout the Amatrice seismic sequence was recorded from 24 August 2016. On 27 May 2016 other experiments were conducted by moving the sensors from layout $L_{2}$ to three other configurations in order to improve the mode shapes mapping. The layouts of these experiments, named $T_{1}, T_{2}$ and $T_{3}$, are shown in Figure 5 . In all the experiments the sampling frequency was set to $100 \mathrm{~Hz}$.

\section{Data analysis}

In Operational Modal Analysis (OMA) the modal parameters of a structure are calculated from vibration data measured under operational conditions [18]. The structure, subjected to unknown input, is modelled in the time domain as a discrete linear time-invariant system whose dynamic behaviour is governed by the following state-space model:

$$
\begin{aligned}
\mathbf{x}_{k+1} & =\mathbf{A} \mathbf{x}_{k}+\mathbf{w}_{k}, \\
\mathbf{y}_{k} & =\mathbf{C} \mathbf{x}_{k}+\mathbf{v}_{k},
\end{aligned}
$$

where $\mathbf{x}_{k} \in \mathbb{R}^{n}$ is the state of the system at the $k^{\text {th }}$ time, $\mathbf{y}_{k} \in \mathbb{R}^{n_{y}}$ is the measured output vector, and $\mathbf{w}_{k} \in \mathbb{R}^{n}$ and $\mathbf{v}_{k} \in \mathbb{R}^{n_{y}}$ are the process noise and output noise, respectively. Since the spectrum of the ambient excitation, included in $\mathbf{w}_{k}$, typically has no dominant frequency components, and $\mathbf{v}_{k}$ is the measurements error, quantities $\mathbf{w}_{k}$ and $\mathbf{v}_{k}$ are modelled as white noise random processes. The $n \times n$ matrix $\mathbf{A}$ and the $n_{y} \times n$ matrix $\mathbf{C}$ are the system matrices.

Stochastic Subspace identification (SSI) is a widespread OMA method in the time domain [15], [19]. In this paper we make use of the covariance driven SSI algorithm (SSI-cov) implemented in the MACEC code [20], [22], [19]. The SSI-cov algorithm calculates matrices by using the covariance functions of the measured output vectors $\mathbf{y}_{k}$. The SSI-cov method allows for determining the system's modal characteristics (frequencies, modal damping ratios and mode shapes) from the eigenvalues decomposition of $\mathbf{A}$. The model order $n$ is linked to the number of system modes (a system with a model order $n$ has $n / 2$ modes). Usually, the system matrices $\mathbf{A}$ and $\mathbf{C}$ are estimated for many model orders and the corresponding modal characteristics are calculated. Modes that appear at many orders are called stable 
modes and are reported in the stabilization diagram, together with the corresponding frequencies and damping ratios.

The velocities recorded by the monitoring system have been processed through the SSI-cov method. The records have been divided into short sequences, each lasting one hour. The effects of swinging bells have been removed before processing. Then, the natural frequencies, mode shapes and damping ratios have been calculated from each sequence. The data have been processed through an automatic procedure implemented in the MACEC code. To automatically detect the stable modes [14], the following criteria have been used:

$$
\begin{gathered}
\delta f \leq 0.1 \%, \quad \delta \zeta \leq 5 \%, \quad \delta m=100 \times(1-M A C) \leq 1 \% \\
\mathrm{MPC} \geq 0.9, \quad n_{s} \geq 8,
\end{gathered}
$$

where $\delta f, \delta \zeta$, and $\delta m$ represent, respectively, the frequency, damping ratio and mode shapes relative differences calculated between poles identified at a certain order and poles identified at the previous order, and MAC is the Modal Assurance Criterion [13]. The integer $n_{s}$ is the number of times for which a pole appears in the stabilization diagram. The conditions on the Modal Phase Collinearity (MPC) enable considering only modes with relevant real components.

Figures 6 and 7 show plots of the tower's first four frequencies vs. time for the entire monitoring period (October 2015 - October 2016). The seasonal effects can be recognized in the data, which exhibit a sinusoidal behaviour over the course of the year. The dependence of the frequencies on temperature is shown in Figures 8 for the one year monitoring period. The first four frequencies (blue line) and the temperature (red line) measured in January 2016 are plotted in Figure 9. The Figures clearly highlight the influence of the temperature. As reported in Table 1, the relative differences $\Delta$ of the frequencies (evaluated on the 1st and 99th percentile) are in the order of $5 \%-6 \%$. These variations confirm the results reported in [23]. Daily variations in the frequency values have also been measured [1]; the maximum variations in this case are in the order of $2 \%-3 \%$. Figure 8 shows the squared correlation coefficients [3]: the first two frequencies depend almost linearly on temperature, while the third and the fourth frequencies are less linearly correlated to temperature. Moreover, the first two natural frequencies are differently influenced by temperature; this could be attributed 


\begin{tabular}{c|ccccccc} 
Mode & \multicolumn{7}{|c}{ Natural frequencies } \\
\hline & $\operatorname{Min}[\mathrm{Hz}]$ & $\operatorname{Min}_{1}[\mathrm{~Hz}]$ & $\operatorname{Avg}[\mathrm{Hz}]$ & $\operatorname{Max}_{99}[\mathrm{~Hz}]$ & $\operatorname{Max}[\mathrm{Hz}]$ & $\Delta[\%]$ & $\tilde{\sigma}[\mathrm{Hz}]$ \\
\hline 1 & 1.020 & 1.074 & 1.099 & 1.132 & 1.197 & 5.42 & 0.013 \\
\hline 2 & 1.251 & 1.342 & 1.382 & 1.429 & 1.449 & 6.50 & 0.018 \\
\hline 3 & 3.003 & 3.376 & 3.447 & 3.560 & 3.931 & 5.44 & 0.041 \\
\hline 4 & 4.078 & 4.522 & 4.614 & 4.787 & 4.980 & 5.85 & 0.051 \\
\hline
\end{tabular}

Table 1: The tower's natural frequencies calculated via the SSI-cov algorithm during the one year monitoring period: minimum, 1st percentile, average, 99th percentile, maximum values, relative differences $\Delta=\left(\operatorname{Max}_{99}-\operatorname{Min}_{1}\right) / \operatorname{Min}_{1}$, standard deviations $\tilde{\sigma}$.

to the different behaviour of the church-tower system in the two directions. As observed in other long-term vibration monitoring of ancient buildings [17], [7], [27], all frequencies tend to increase with temperature, as an effect of closing of micro-cracks due to the thermal expansion. A different behaviour has been highlighted in [28], where the torsional mode of the bell tower exhibits an opposite trend, as an effect of the thermally-induced slackening of some reinforcements elements acting on the transversal section. With regard to Figure 9, temperatures are higher than $0^{\circ} \mathrm{C}$ and go below in five days for only a few hours a day. The drastic change in frequencytemperature correlation found in [28] in freezing conditions, with frequencies increasing with decreasing temperatures, is not so evident in this case, although a similar trend can be recognized in the coldest days, when the mean daily temperature decrease below $2^{\circ}$.

The SSI-cov method, as implemented in the MACEC code, allows for calculating the variances of the estimated modal characteristics as well [19], [22]. These variances represent the statistical uncertainty which is caused by the estimation of the output covariances from the measured output samples and the subsequent propagation of these estimation errors through the SSI-cov algorithm.

As the variations over time of the frequencies measured on the San Frediano bell tower are small, a comparison with the errors calculated via the SSI-cov algorithm has been performed. Figure 10 shows the histogram of the standard deviations $\sigma$ of the tower's first four natural frequencies calculated by MACEC. Most (more than 90\%) of the first three frequencies exhibit $\sigma$ values ranging between $0.001 \mathrm{~Hz}$ and $0.005 \mathrm{~Hz}$. The fourth frequency exhibits 
higher $\sigma$ values, between $0.01 \mathrm{~Hz}$ and $0.07 \mathrm{~Hz}$. A comparison with the data in Table 1 clearly shows that the variations over time of the fourth frequency are in the same order as the estimation inaccuracies, while for the first three frequencies the estimation inaccuracies are one order of magnitude below the environmental variations. This larger estimation inaccuracy for the fourth frequency could be due to the fact that the corresponding mode is less well excited than the others. Figures 11 and 12 show the tower's modal damping ratios calculated for the first four frequencies vs. time and temperature, respectively. The data on damping appear much more dispersed with respect to the corresponding values of the natural frequencies, revealing amplitude variations of up to $80 \%$. Moreover, the uncertainties on the estimation of the modal damping ratios are generally larger than those of the frequencies and mode shapes. As in the case of the frequencies, the damping ratios tend to increase with temperature. 

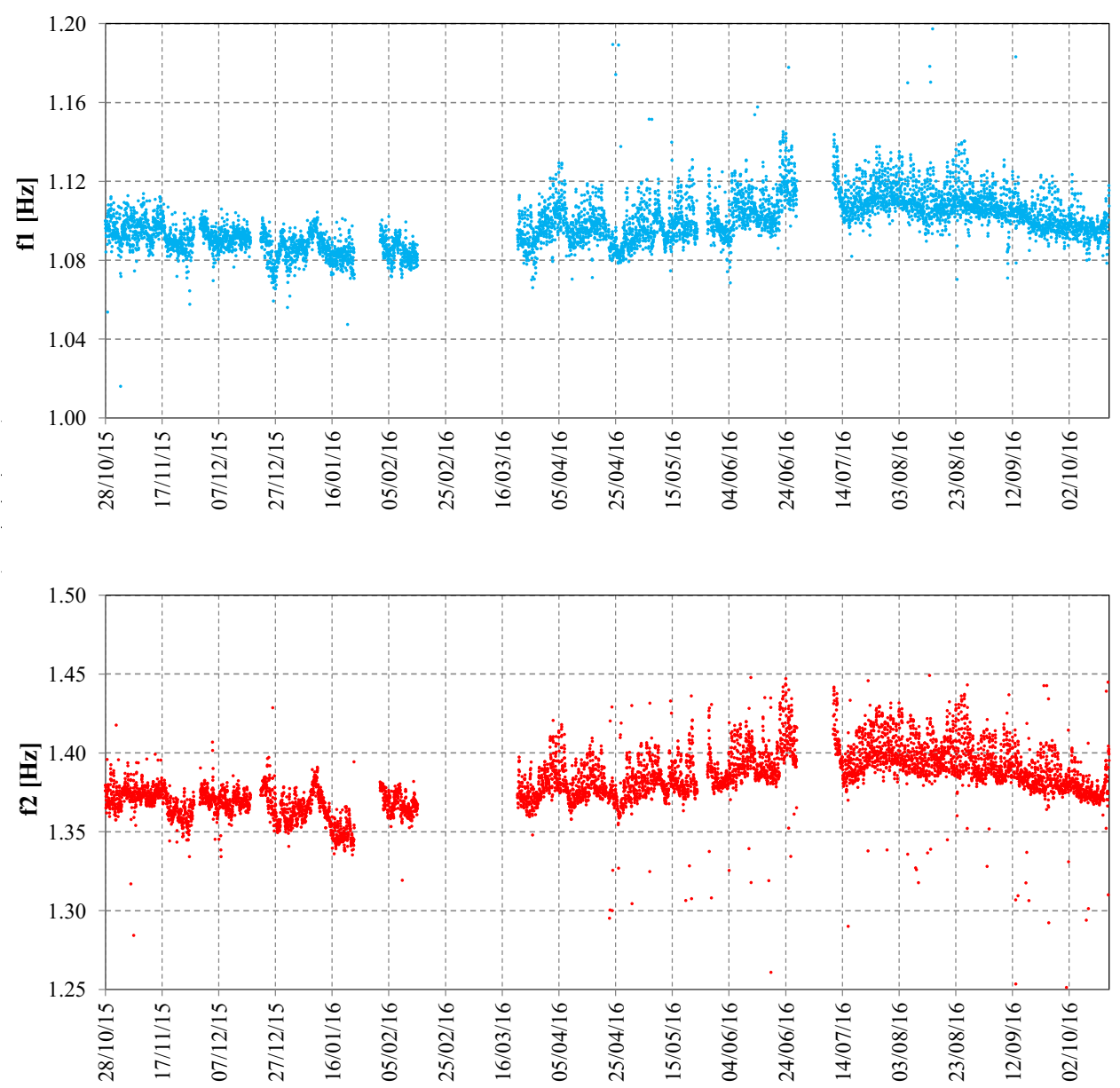

Figure 6: The tower's first two natural frequencies measured during the monitoring period (October 2015 - October 2106) 

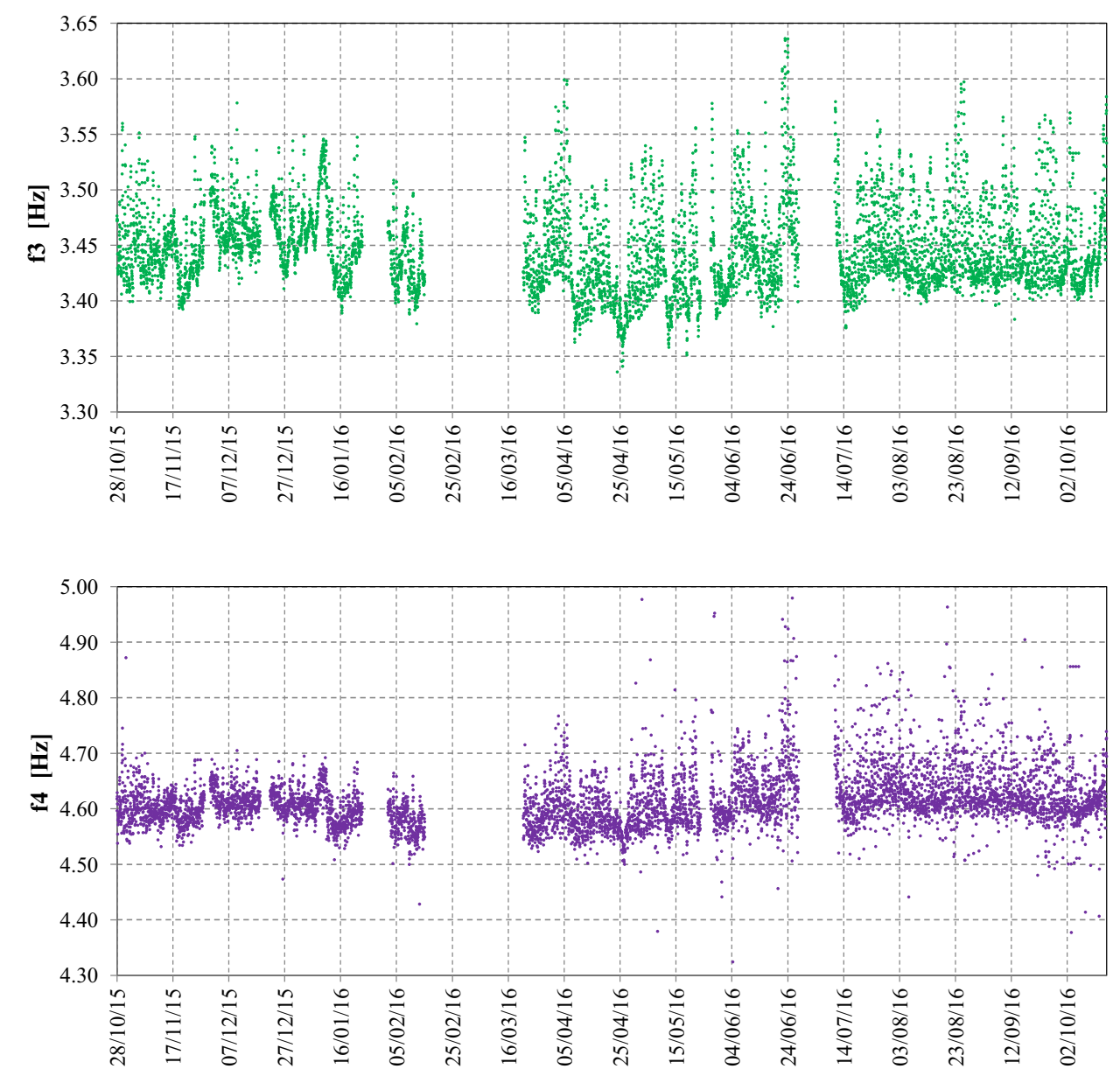

Figure 7: The tower's third and fourth natural frequencies measured during the monitoring period (October 2015 - October 2106) 


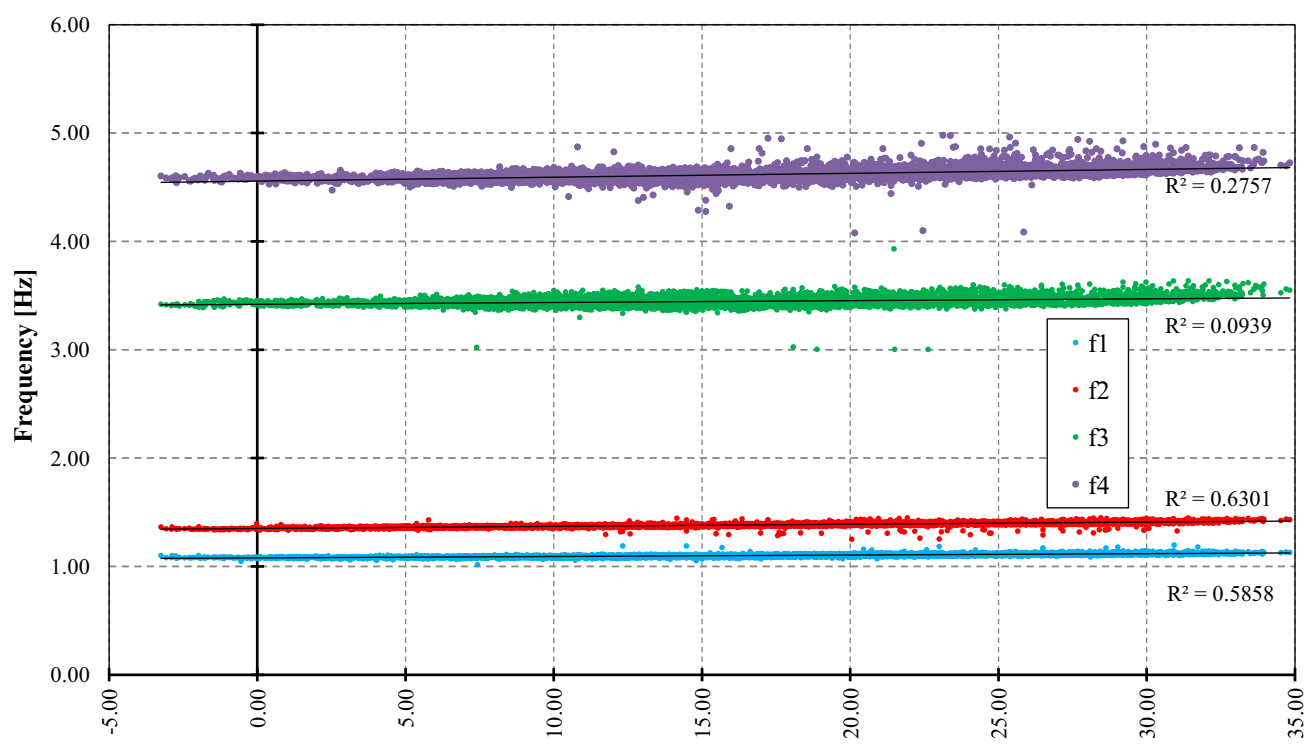

Temperature $\left[{ }^{\circ} \mathrm{C}\right]$

Figure 8: The tower's first four frequencies plotted vs. temperature. 

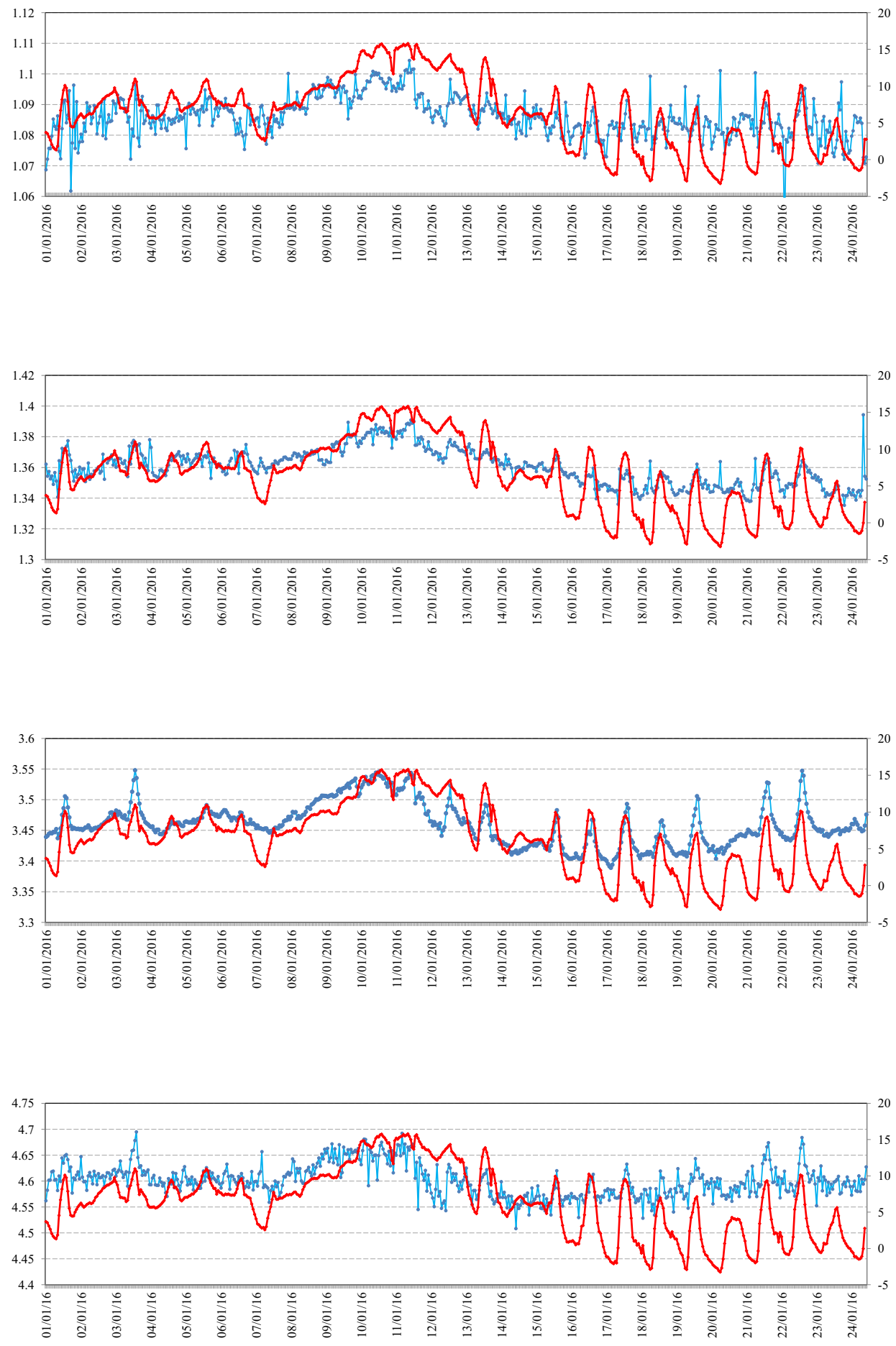

16

Figure 9: The tower's first four natural frequencies (blue line) and the temperature values (red line) measured during January 2016. 


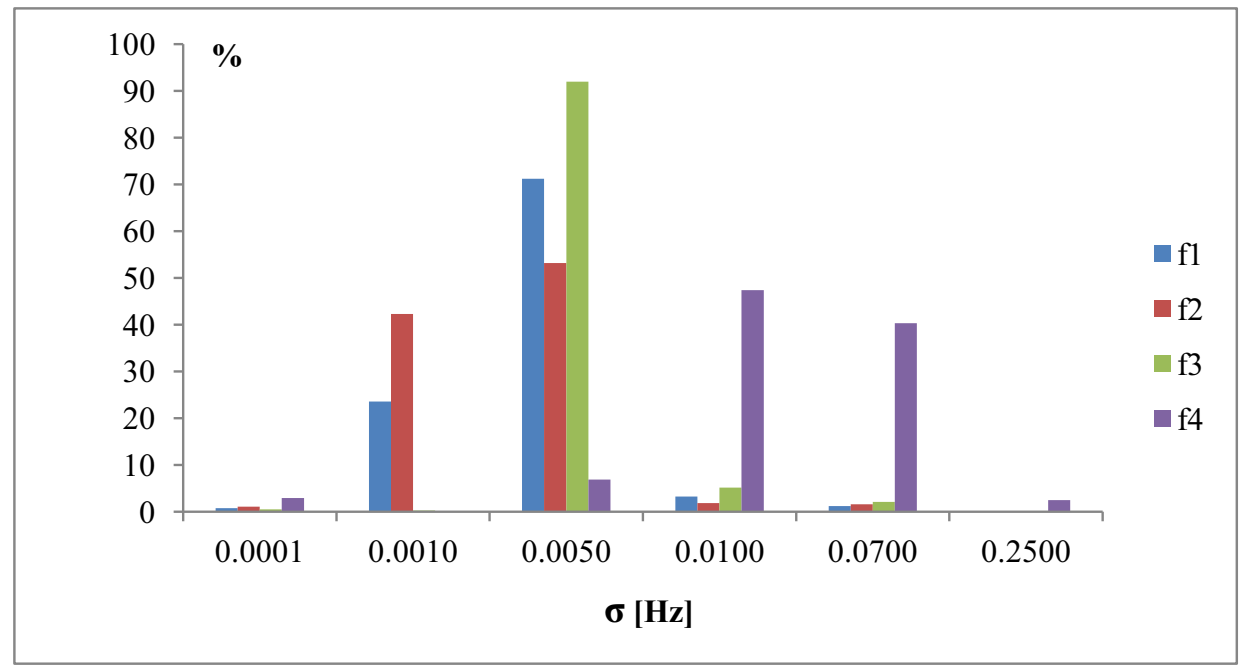

Figure 10: Histogram of the estimated standard deviations of the tower's first four frequencies. 


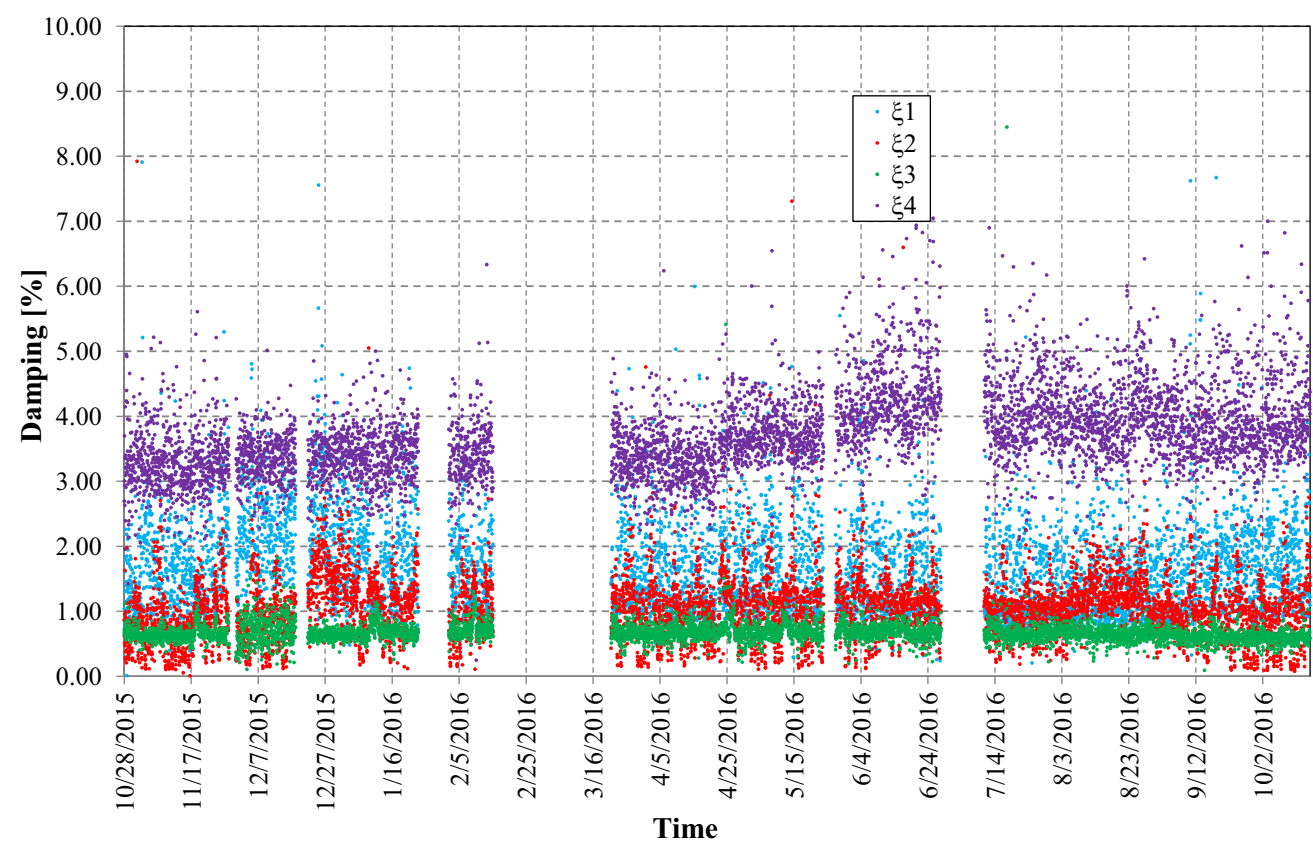

Figure 11: Damping ratios of the tower's first four mode shapes measured during the monitoring period (October 2015-October 2106). 


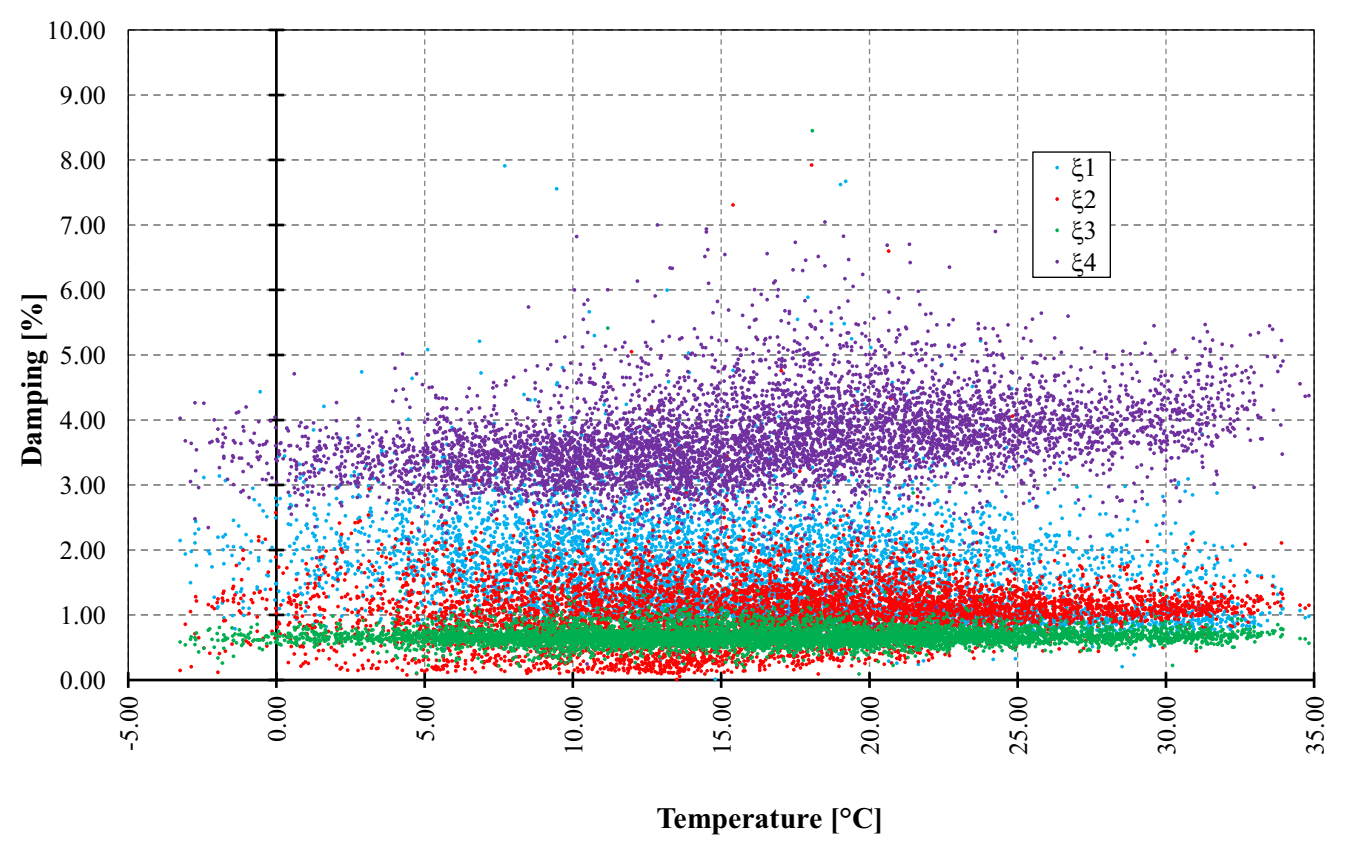

Figure 12: Damping ratios of the tower's first four mode shapes vs. temperature. 

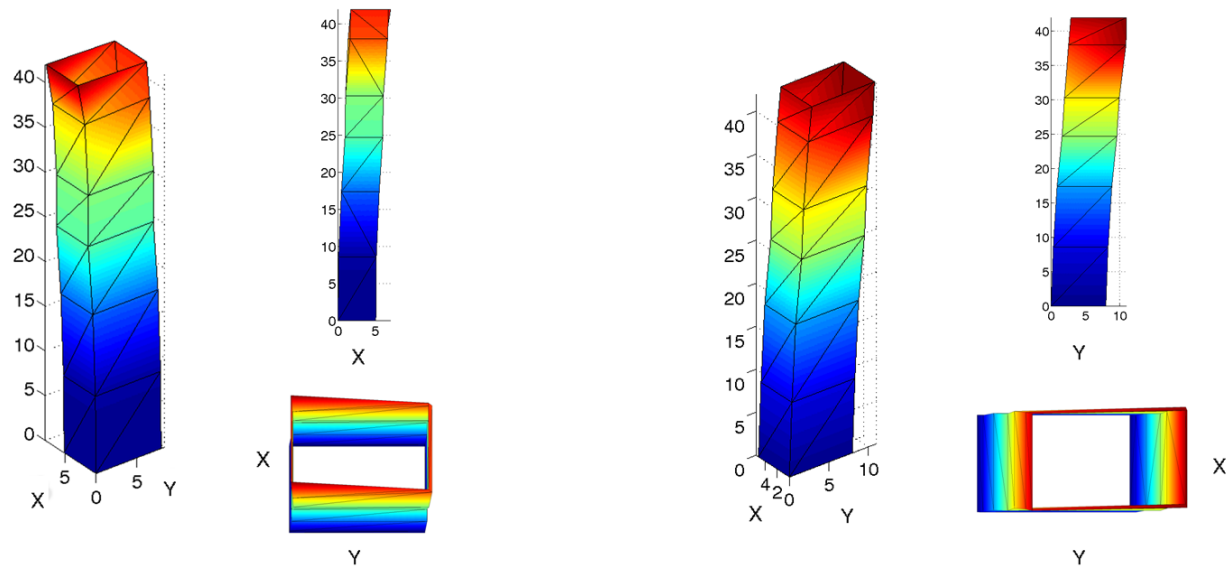

Figure 13: The first (bending along $x$ ) and second (bending along $y$ ) identified mode shapes.

With regard to mode shapes, in order to evaluate the variation of the mode shapes with temperature, we have calculated the MAC value between the mode shapes corresponding to the minimum $\left(-3{ }^{\circ} \mathrm{C}\right)$ and maximum $(+27$ $\left.{ }^{\circ} \mathrm{C}\right)$ temperature reached with layout $L_{2}$, for the four frequencies. These values range from 0.9891 to 0.9981 , thereby suggesting the substantial lack of dependence of the mode shapes on temperature.

The data from the different sensor layouts $\left(L_{2}\right.$ in Figure 4 and $T_{1}, T_{2}$, $T_{3}$ in Figure 5) have been superposed, and the resulting mode shapes are shown in Figures 13 and 14. In particular, Figure 13 shows the first two bending modes. Figure 14 shows the third torsional mode and the fourth bending mode along $x$. For the sake of comparison, Figure 15 reports the first four mode shapes calculated by the finite-element code NOSA-ITACA via model updating procedures [1], [16], the bell tower being discretized into 18500 thick shell elements [4]. The corresponding numerical frequencies are $1.17 \mathbf{H z}, 1.37 \mathbf{H z}, 3.34 \mathbf{H z}$ and $5.05 \mathrm{~Hz}$, respectively. The MAC values between the identified and numerical mode shapes are greater than 0.94 . 

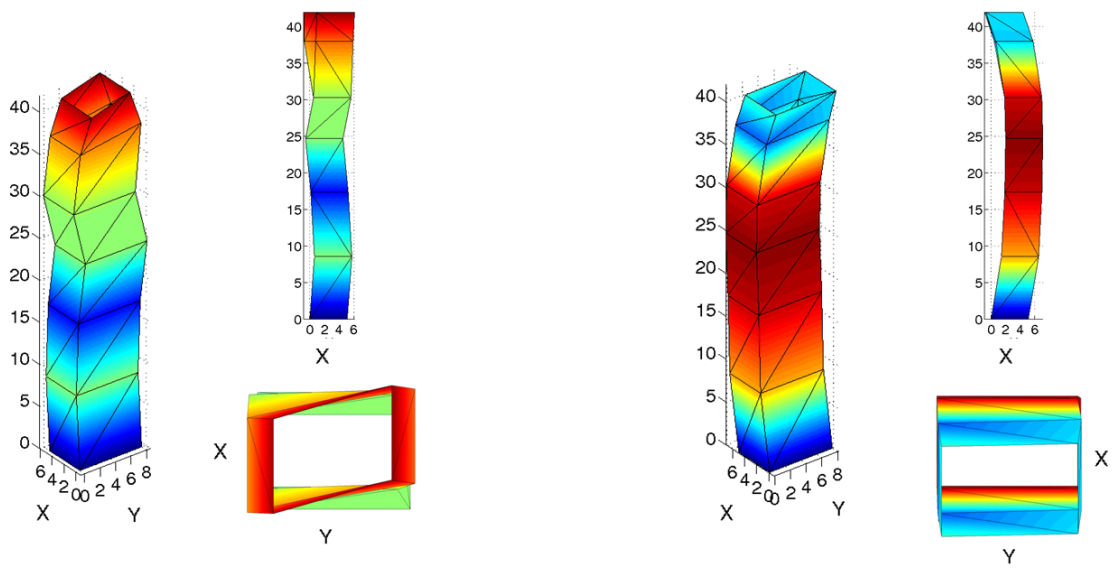

Figure 14: The third (torsional) and fourth (bending along $x$ ) identified mode shapes.

\section{Assessment of environmental effects}

In this Section the effects of environmental changes on the natural frequencies of the San Frediano bell tower are taken into account. In particular, in Subsection 4.1 an ARX model is used to assess the dependence of the tower's natural frequencies on the air temperature. The temperature values measured during the monitoring period by a sensor located in the Lucca Botanic Garden (near the tower) constitute the input of the model; the output is given by the measured natural frequencies of the tower (see Figure 8). In Subsection 4.2 an output-only procedure instead applies, able to automatically remove the environmental effects and the operational influences from the data and thus detect abnormal changes in the tower's dynamic behaviour. Output-only means that only the tower's natural frequencies are required, without any explicit information on the environmental conditions. This approach turns out to be useful in this monitoring campaign, in which environmental sensors were not placed exactly on the tower. In both methods only the first three natural frequencies have been taken into account, in consideration of the high estimation inaccuracies evidenced in the calculation of the fourth frequency (see Figure 10). 

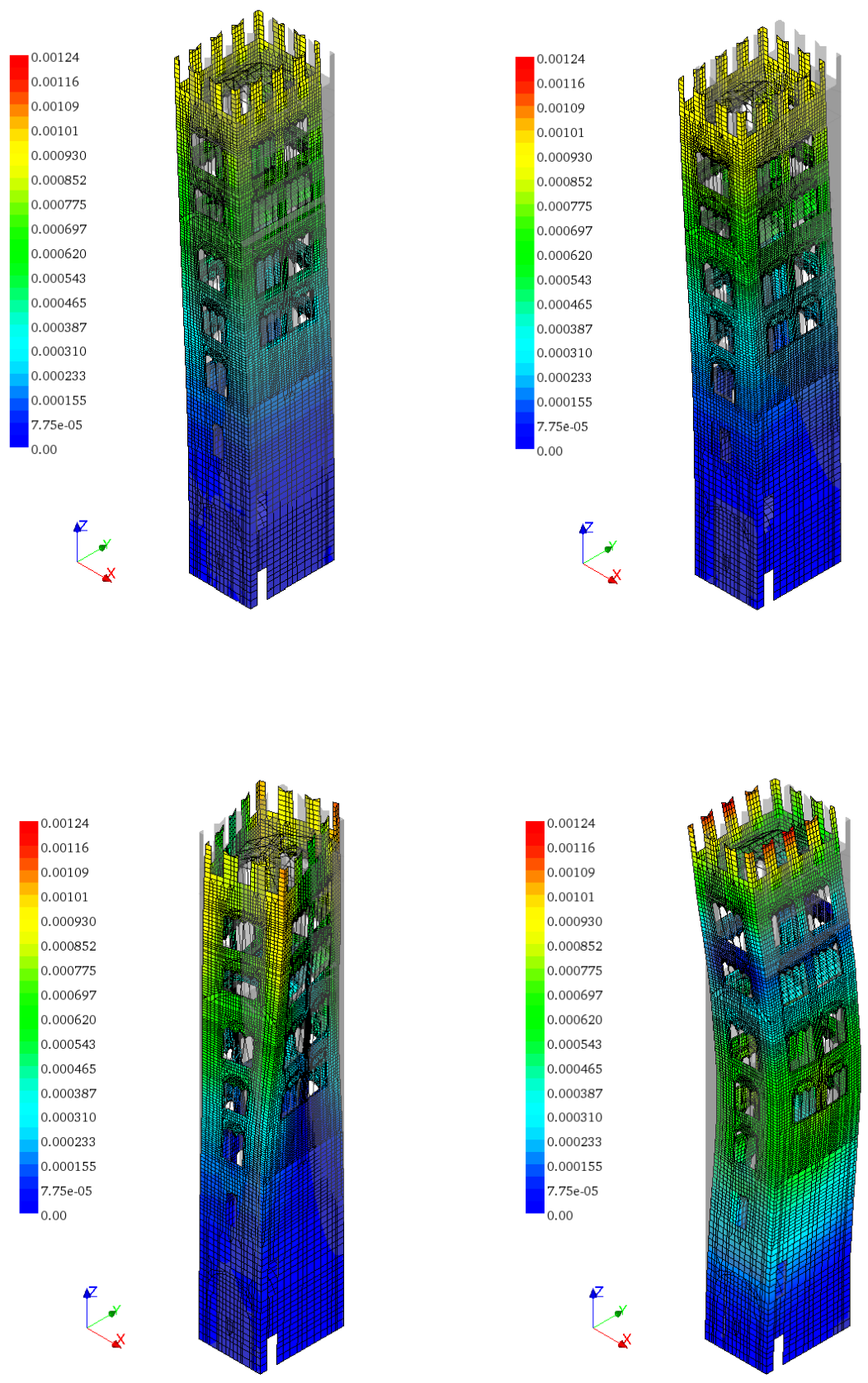

Figure 15: The first four mode shapes computed via finite-elements. 


\begin{tabular}{c|cccc|cccc} 
Mode & \multicolumn{4}{|c|}{ ARX model } & \multicolumn{4}{c}{ Static regression model } \\
\hline & $n_{a}$ & $n_{b}$ & $n_{k}$ & $\hat{\lambda}$ & $n_{a}$ & $n_{b}$ & $n_{k}$ & $\hat{\lambda}$ \\
\hline 1 & 2 & 5 & 0 & $3.05 \cdot 10^{-5}$ & 0 & 1 & 0 & $5.98 \cdot 10^{-5}$ \\
\hline 2 & 4 & 1 & 1 & $1.21 \cdot 10^{-4}$ & 0 & 1 & 0 & $1.55 \cdot 10^{-4}$ \\
\hline 3 & 2 & 6 & 2 & $6.87 \cdot 10^{-3}$ & 0 & 1 & 0 & $1.60 \cdot 10^{-3}$ \\
\hline
\end{tabular}

Table 2: Comparison between ARX and static regression models for the first three natural frequencies of the San Frediano bell tower.

\subsection{ARX models}

This Subsection reports the main features of the Auto-Regressive output and eXternal input (ARX) model [11] and the results obtained. The model is described by the following relation between the output $y_{k}$ (in this case a natural frequency) and the input $u_{k}$ (in this case air temperature) at the instant $k$ :

$y_{k}+a_{1} y_{k-1}+\cdots+a_{n_{a}} y_{k-n_{a}}=b_{1} u_{k-n_{k}}+b_{2} u_{k-n_{k}-1}+\cdots+b_{n_{b}} u_{k-n_{k}-n_{b}+1}+e_{k}$,

where $n_{a}$ is the auto-regressive order, $n_{b}$ the exogeneous order, $n_{k}$ the time delay between input and output, $e_{k}$ an error term, modelled as white Gaussian noise in which the unknown inputs and measurement noise are included. In the equation, the input and output data have been reduced to a zero mean. In particular, by putting $\left[n_{a}, n_{b}, n_{k}\right]=[0,1,0]$, equation (5) reduces to a static regression model. For each frequency, the loss function $\hat{\lambda}[14]$ has been minimized, via specific functions implemented in MatLab, in order to choose the optimal values of the triad $\left[n_{a}, n_{b}, n_{k}\right]$. The calculations have been performed over the training period from October 2015 to June 2016. Table 2 reports, for each of the tower's three natural frequencies, the optimal values of the ARX model orders and the corresponding values of $\hat{\lambda}$, together with the results of the corresponding static regression models. The very low values of $\hat{\lambda}$ indicate that very accurate models have been found. Little loss of accuracy is evidenced when passing from ARX models to static models, except for the third frequency, which appears to depend nonlinearly on temperature.

Figure 16 shows plots of the tower's natural frequencies vs. temperature for the entire monitoring period. Blue indicates the experimental values, red the values simulated via the ARX models. The static regression lines 
are also plotted in blue. Figure 17 shows the simulation errors vs. time, calculated as the difference between the experimental and the simulated values of the tower's frequencies. The red dashed lines represent the 95 percent confidence interval [3], [14]. The vertical red lines on the Figure split the errors in two parts: the training period lasting about eight months (from October 2015 to June 2016) and the subsequent validation period, containing the Amatrice earthquake. According to the criterion stated in [14], if a simulation error exceeds the confidence interval, it is likely that something happened to the tower. As suggested by visual inspection, no systematic tendencies in the frequency variations are revealed by the figures. The errors on the third frequency, whose dependence on temperature seems to deviate from linearity, are larger than those related to the other frequencies.

\subsection{Kernel principal component analysis}

Kernel principal component analysis (kernel PCA) is here used to detect the existence of a novelty in measured data by comparing them with the values predicted by a model calibrated on suitable training data [9], [24]. The method is based on a nonlinear relationship between the measured output and the unknown changing environmental conditions and described in [21], where it is applied for structural health monitoring purposes on a post-tensioned concrete bridge.

Kernel PCA is a nonlinear generalization of linear PCA. The basic idea is to map data $\hat{\mathbf{y}}_{i}, i=1 \ldots n_{s}$ (with $n_{s}$ number of data samples) from measurements into a high (or infinite) dimensional space $\mathcal{F}$ via a nonlinear function $\Phi$, $\hat{\mathbf{z}}_{i}=\Phi\left(\hat{\mathbf{y}}_{i}\right)$, and calculate the singular value decomposition of the matrix $\mathbf{Z}$, whose columns are the images $\hat{\mathbf{z}}_{i}$ of the training data through $\Phi, i=1 \ldots n_{t}$, with $n_{t} \leq n_{s}$. We denote by $\mathcal{U}_{m}$ the subspace of $\mathcal{F}$ spanned by the eigenvectors of the correlation matrix $\mathbf{Z} \mathbf{Z}^{*}$ corresponding to the $m$ largest singular values of $\mathbf{Z}$. Given the approximation $\tilde{\mathbf{z}}_{i}$ of $\Phi\left(\hat{\mathbf{y}}_{i}\right), i=1 \ldots n_{s}$, if an anomaly occurs after the training interval, the measured data $\hat{\mathbf{z}}_{i}$ for $i \geq n_{t}$ will not belong to $\mathcal{U}_{m}$. Thus, the novelty index (or misfit) $\left\|e_{i}\right\|$ can be defined as the norm of the projection of the error $\hat{\mathbf{z}}_{i}-\tilde{\mathbf{z}}_{i}$ onto the orthogonal complement to $\mathcal{U}_{m}$ in $\mathcal{F}$. If $\tilde{\mathbf{z}}_{i}$ is a good approximation of $\hat{\mathbf{z}}_{i}$, then $\left\|e_{i}\right\|$ is small. Changes occurring in $\hat{\mathbf{z}}_{i}$ are evidenced by values of $\left\|e_{i}\right\|$ approaching to 1 .

In [21] a Matlab tool based on Gaussian kernel PCA has been developed and applied to a three-span post-tensioned concrete bridge monitored for one year. In this Section, the numerical tool described in [21] is applied to the 

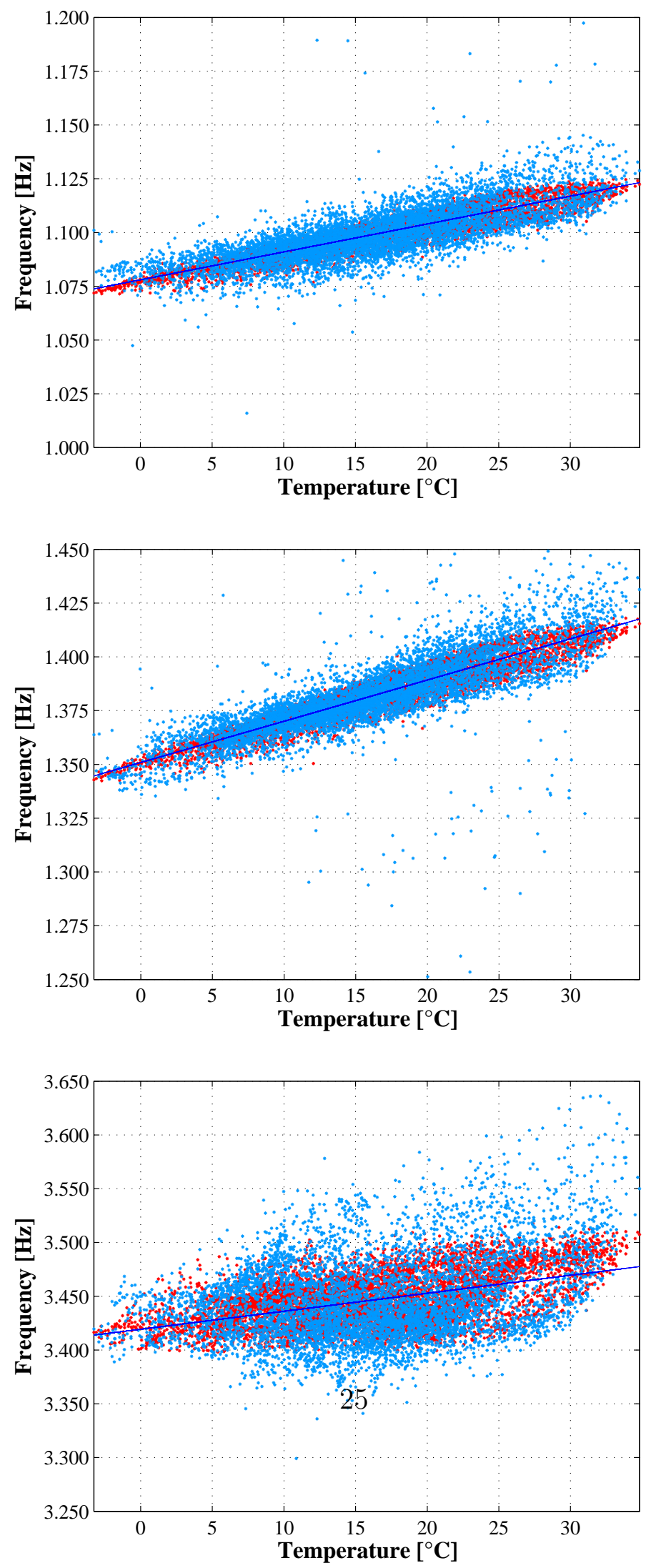

Figure 16: The tower's first three natural frequencies vs. temperature (first frequency on the top). Blue dots: measured values. Red dots: values given by the ARX model. Blue line: static regression line. 

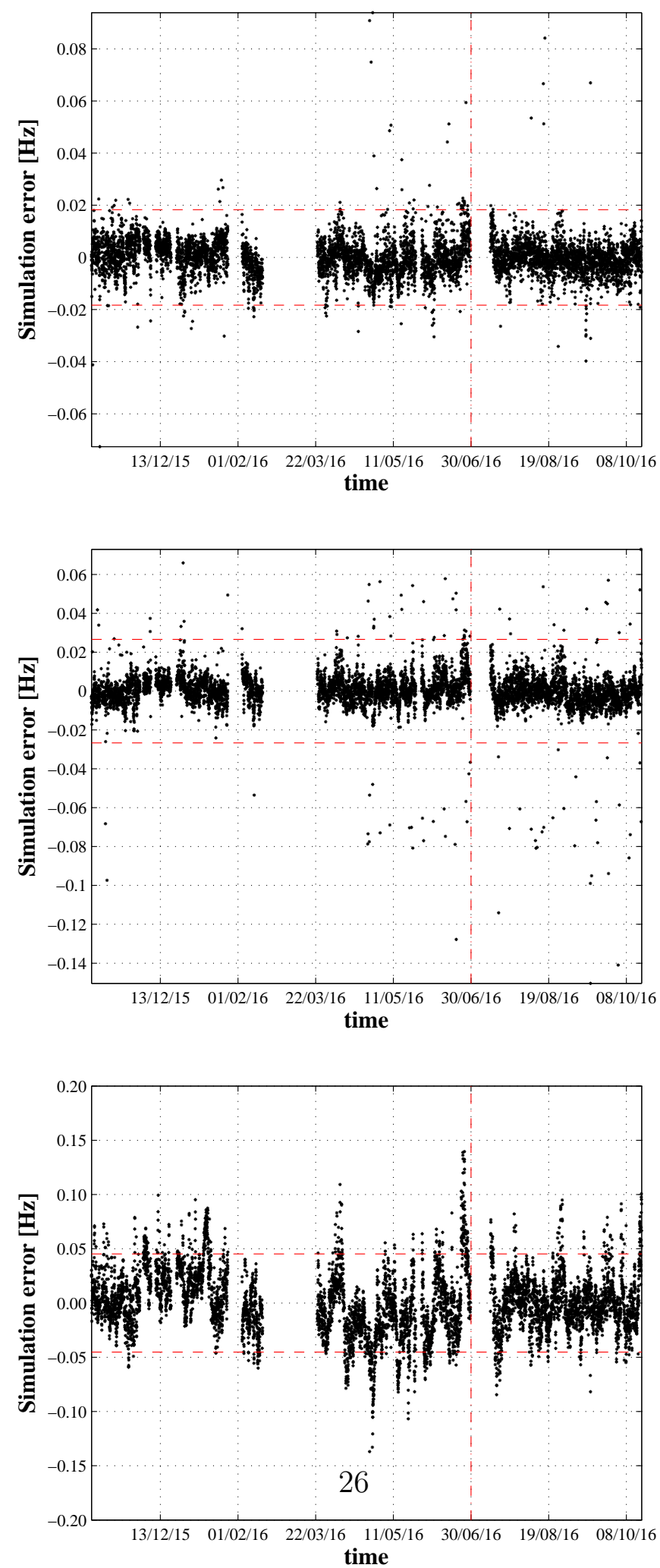

Figure 17: Simulation error of the first three frequencies vs. time (first frequency on the top). The red horizontal dashed lines indicate the 95 percent confidence interval. The vertical line indicates the training period. 
San Frediano bell tower considering its first three natural frequencies. For the sake of comparison, the results obtained with linear PCA are also reported. As only three frequencies are available, the number $m$ of retained principal components in linear PCA can be equal to 1 or 2 ; the best results have been obtained for $m=2$ and are reported in the following.

Firstly, a training set of $n_{t}=5500$ data points has been considered, corresponding to all the measurements recorded before the Amatrice earthquake. This particular value of $n_{t}$ allows for assessing the tower's structural conditions before and after the seismic event. The corresponding results are shown in Figure 18 for the linear and the kernel procedure. In order to highlight a possible novelty in the structural behaviour of the tower and compare the results obtained via linear and Kernel PCA, the 95th percentile of the misfits has been evaluated for the training period (the red horizontal line in the Figure). Then, considering data measured after the Amatrice earthquake, the percentage $N_{95}$ of points exceeding the threshold of the 95th percentile has been evaluated: a percentage greater than $5 \%$ indicates a novelty in the tower's behaviour. As expected, results of both linear and kernel PCA indicate that negligible damage seems to be occurred to the tower as a consequence of the earthquake.

Figure 19 illustrates the application of these procedures to a simulated damage scenario suggested by the results shown in [7], where a slight decrease has been observed in the natural frequencies of the Gabbia tower (Mantua) after a seismic event. In Figure the training period coinciding with the entire monitoring period (blue dots) has been replicated (green dots) by assigning a decrease of $2 \%, 1 \%$ and $0.5 \%$ to the first, second and third natural frequency. These values correspond to those observed for the first two bending modes and the fourth torsional mode of the Gabbia tower after the seismic event. The results are shown for the linear (top) and the kernel (bottom) PCA. The percentage $N_{95}$ of points exceeding the threshold (horizontal red line) calculated as the 95th percentile of the misfit on the whole training period is $47.84 \%$ for linear PCA and $\mathbf{4 0 . 5 0 \%}$ for Kernel PCA. Results of linear and Kernel PCA are then comparable and clearly indicate a novelty in the tower's dynamic behaviour, in spite of the slight decrease assigned to the frequencies, in the order of the variations induced by tem- 
perature fluctuations. In Figure 20 a more severe damage scenario is presented, in which the first, the second and the third natural frequencies are reduced by $4 \%, 2 \%$ and $1 \%$, respectively. The corresponding misfits increase and PCA is proved to be an effective tool for damage detection, with $N_{95}=\mathbf{9 8 . 5 5 \%}$ for linear PCA and $N_{95}=97.23 \%$ for Kernel PCA. As far as the training period is concerned, several calculations with different durations have been carried out, yielding different accuracies in estimating anomalous frequency changes. In fact, misfits calculated for training periods shorter than one year do not contain all the information about seasonal changes. 

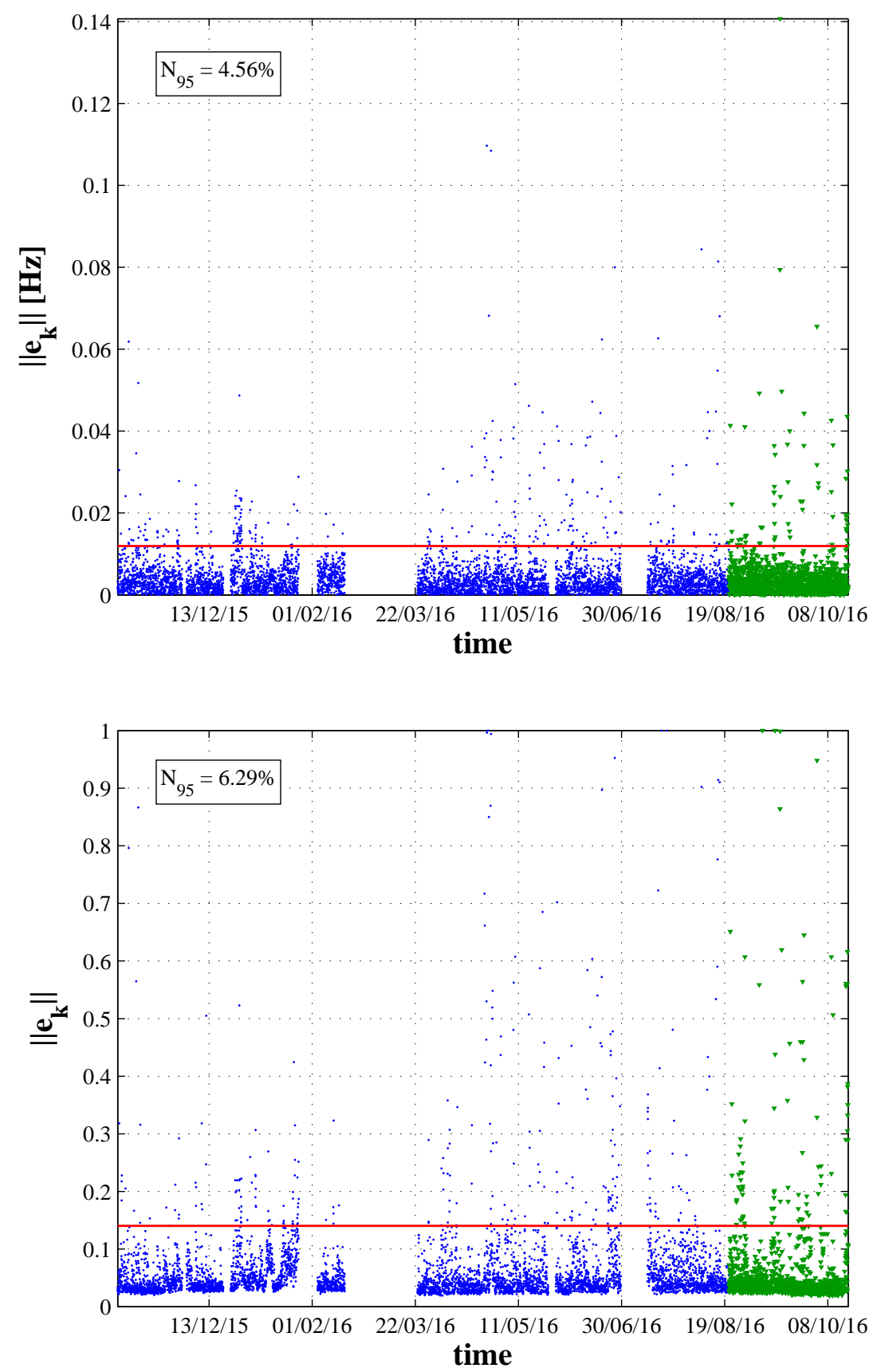

Figure 18: Misfit of the linear (top) and kernel (bottom) PCA trained with the data obtained before the Amatrice earthquake (blue dots). 

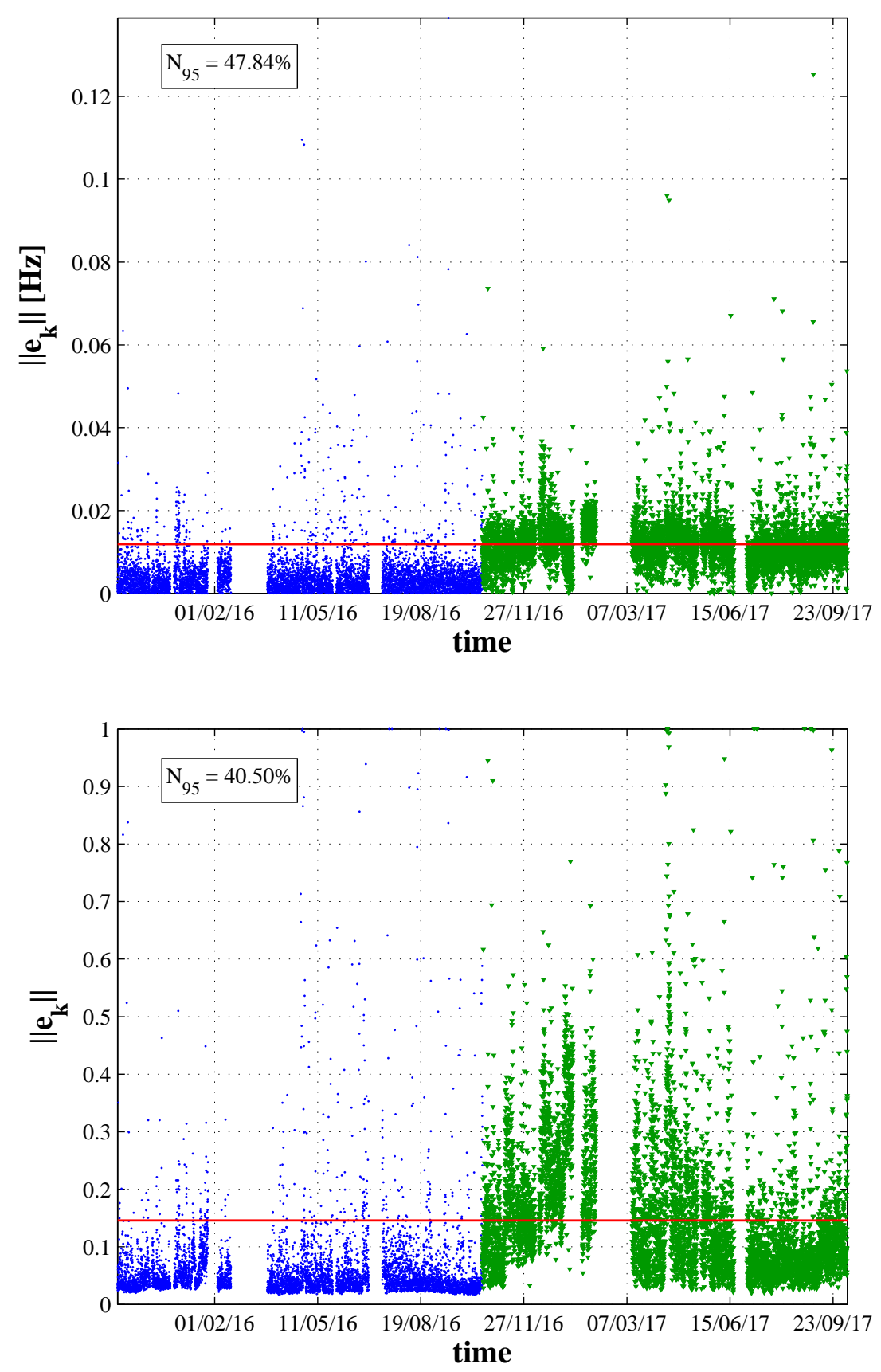

Figure 19: Misfit of the linear (top) and kernel (bottom) PCA for the entire data point training period (blue dots). Green dots refer to a decrease of $2 \%, 1 \%$ and $0.5 \%$ in the first, second and third frequency, respectively. 

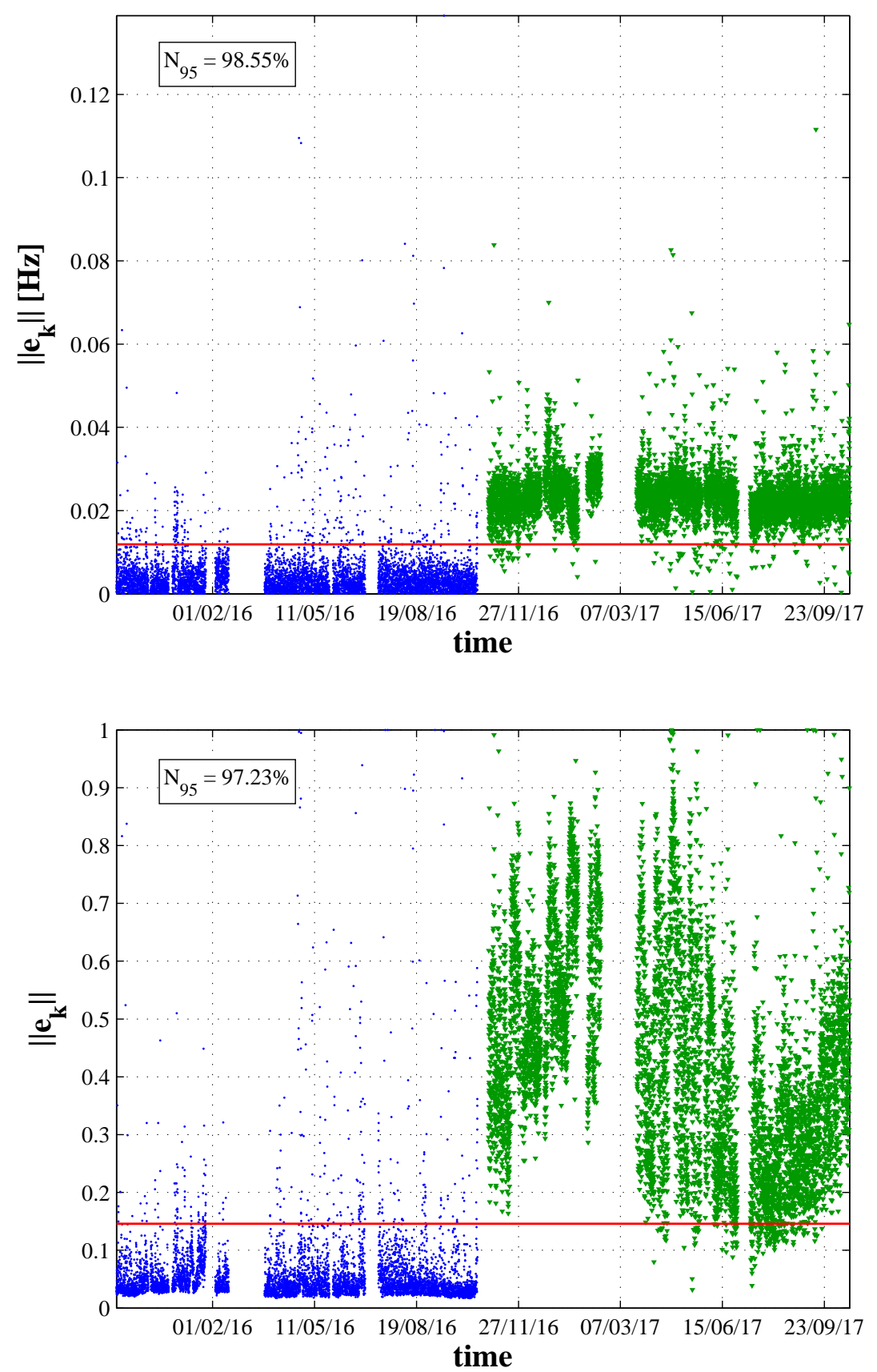

Figure 20: Misfit of the linear (top) and kernel (bottom) PCA for the entire data point training period (blue dots). Green dots refer to a decrease of $4 \%, 2 \%$ and $1 \%$ in the first, second and third frequency, respectively. 


\section{Conclusions}

Continuous ambient vibration monitoring is a powerful instrument for safeguarding ancient buildings and monuments. This paper describes the results of a long-term monitoring of the San Frediano bell tower in Lucca (Italy). The tower, dating back to the 11th century, has been fitted along its height with four triaxial seismometric stations, which were left active on the structure for about one year. Data from the monitoring system have been processed via the Stochastic Subspace Identification Method in order to identify the tower's modal characteristics and their variations over the year. The dependence of the tower's frequencies on the ambient temperature has been first studied and simulated via simple auto-regressive models. Once the influence of environmental factors has been accounted for, changes in the tower's dynamic properties over time can represent effective structural damage indicators. In order to remove the environmental effects, some output-only models based on linear and kernel principal component analyses (PCA) have been applied to the measured natural frequencies. First, data recorded on the tower after the Amatrice earthquake have been analysed, then the procedures have been applied to two virtual damage scenarios inspired by real damages observed in a bell tower in Northern Italy after a seismic event.

The main results obtained in the paper can be summarized as follows:

- The variation in the tower's natural frequencies during the year are in the order of $5 \%-6 \%$. Mode shapes do not exhibit significant variations.

- A clear correlation between the tower's natural frequencies and air temperature has been recognized. As observed in previous papers, frequencies increase as temperature increases; this behaviour can be explained with the closure of microcrack due to the thermal dilatation of the materials constituting the tower. The dependence of the first and second bending frequencies on the temperature is almost linear, on the contrary the dependence of third frequency, associated to the torsional mode, deviates from linearity. 
- With regard to damage detection, PCA turned out to be an effective tool for detecting even slight changes in the tower's dynamic behaviour, in spite of the small number of monitored frequencies.

Acknowledgements. This research has been supported by the Region of Tuscany (Project "MOSCARDO - ICT technologies for structural monitoring of age-old constructions based on wireless sensor networks and drones", 20162018). This support is gratefully acknowledged.

\section{References}

[1] R.M. Azzara, G. De Roeck, M. Girardi, C. Padovani, D. Pellegrini, E. Reynders, Assessment of the dynamic behaviour of an ancient masonry tower in Lucca via ambient vibrations, Structural Analysis of Historical Constructions. Anamnesis, diagnosis, therapy, controls, Koen Van Balen and Els Verstrynge Eds., Taylor \& Francis Group, Print ISBN: 978-1138-02951-4 eBook ISBN: 978-1-317-20662-0, 2016.

[2] R.M. Azzara, L. Zaccarelli, A. Morelli, T. Trombetti, G. Dallavalle, A. Cavaliere and S. Danesi, Seismic moni-toring of the Asinelli and Garisenda medioeval towers in Bologna (Italy), an instrumental contribution to the engi-neering modeling direct to their protection, Proceedings of the second International Conference on Protection of Historical Constructions - PROHITECH 2014, F. M. Mazzolani and G. Altay (eds), Bogaziçi University Publishing, 2014.

[3] Bendat J.S., Piersol A.G. Random Data: Analysis and Measurement Procedures, 4th Edition. ISBN 978-0-470-24877-5, 2010.

[4] Binante V, Girardi M, Padovani C, Pasquinelli G, Pellegrini D, Porcelli M., Robol L. NOSA-ITACA 1.1 documentation 2017. www.nosaitaca.it/software/.

[5] Gentile, C., Saisi A. Ambient vibration testing of historic masonry towers for structural identification and damage assessment. Construction and Building Materials 21.6: 1311-1321, 2007. 
[6] C. Gentile, A. Saisi and A. Cabboi, Dynamic monitoring of a masonry tower. Proceedings of the 8th International Conference on Structural Analysis of Historical Constructions, SAHC 2012, 2012.

[7] Gentile C., Guidobaldi M. and Saisi A., One-year dynamic monitoring of a historic tower: damage detection under changing environment, Meccanica, 51(11):2873-2889, 2016.

[8] Heyman J. and Threlfall B.D. Inertia Forces Due to Bell Ringing. Int. J. of Mech. Sci. 18:161-164, 1976.

[9] Hoffmann H. Kernel PCA for novelty detection. Pattern Recognition 40(3):863-874, 2007.

[10] Ivorra S., Pallares F.J., Dynamic investigations on a masonry bell tower. Engineering Structures 28:660-667, 2006.

[11] Ljung L. System Identification: Theory for the User (2nd edn), PrenticeHall: Upper Saddle River, NJ, USA, 1999.

[12] M. Lucchesi, C. Padovani, G. Pasquinelli and N. Zani. Masonry constructions: mechanical models and numerical applications, Lecture Notes in Applied and Computational Mechanics, Vol. 39, SpringerVerlag, 2008.

[13] Theoretical and Experimental Modal Analysis, Maia N.M.M. and Silva J.M.M. Eds, Research Studies Press LTD., Baldock, Hertfordshire, England, 1997.

[14] Peeters B. and De Roeck G. One-year monitoring of the Z24-Bridge: enviromental effects versus gamage events Earthquake engineering and structural dynamics, 30: 149-171, 2001.

[15] Peeters B., De Roeck G. Reference-based stochastic subspace identification for output-only modal analysis Mechanical systems and signal processing 13.6: 855-878, 1999.

[16] M. Porcelli, V. Binante, M. Girardi, C. Padovani and G. Pasquinelli. A solution procedure for constrained eigenvalue problems and its application within the structural finite-element code NOSA-ITACA. Calcolo, 52(2): 167-186, Springer Milan, 2015. 
[17] L.F. Ramos , L. Marques , P.B. Lourenço , G.De Roeck , A. CamposCosta and J.Roque. Monitoring historical masonry structures with operational modal analysis: two case studies. Mech. Syst. Signal Process. 24: 1291-1305, 2010.

[18] Reynders E. System Identification Methods for (Operational) Modal Analysis: Review and Comparison. Arch Comput Methods Eng 19: 51124, 2012.

[19] Reynders E., Pintelon R., De Roeck G. Uncertainty bounds on modal parameters obtained from stochastic subspace identification Mechanical systems and signal processing 22.4: 948-969, 2008.

[20] Reynders E., Schevenels, M. and De Roeck, G. Macec 3.3. A Matlab toolbox for experimental and operational modal analysis. http://bwk.kuleuven.be/bwm/macec/, 2014.

[21] Reynders E., Wursten G. and De Roeck G. Output-only structural health monitoring in changing environmental conditions by means of nonlinear system identification. Structural Health Monitoring 13(1): 8293, 2014.

[22] Reynders E., Maes K., Lombaert G. and De Roeck G. Uncertainty quantification in operational modal analysis with stochastic subspace identification: Validation and applications. Mech. Syst. Signal Process 66-67:13-30, 2016.

[23] Saisi A., Gentile C. and Guidobaldi M., Post-earthquake continuous dynamic monitoring of the Gabbia Tower in Mantua, Italy, Construction and Building Materials, 81:101-112, 2015.

[24] Schoelkopf B., Smola A., Mueller K.R., Nonlinear component analysis as a kernel eigenvalue problem. Neural Computation, 10(5):1299-1319, 1998.

[25] Selby A.R. and Wilson J.M. The Dynamics of Masonry Bell Towers. In J.W. Bull (ed.) Computational Modelling of Masonry, Brickwork and Blockwork Structures. Saxe-Coburg Publications, 2001.

[26] Tsogka C., Daskalakis E., Comanducci G., and Ubertini F., The stretching method for vibration-based structural health 
monitoring of civil structures, Computer-Aided Civil and Infrastructure Engineering, 32(4): 288-303, 2017.

[27] Ubertini F., Comanducci G. and Cavalagli N. Vibration-based structural health monitoring of a historic bell-tower using output-only measurements and multivariate statistical analysis, Structural Health Monitoring 15(4): 438-457. SAGE, 2016.

[28] Ubertini F., Comanducci G., Cavalagli N., Pisello N., Materazzi A.L. and Cotana, F., Environmental effects on natural frequencies of the San Pietro bell tower in Perugia, Italy, and their removal for structural performance assessment, Mechanical Systems and Signal Processing 82: 307-322, 2017. 